\title{
A IMAGINAÇÃO SOCIOLÓGICA E O SUL DE MINAS
}

\author{
Breno Rafael da Costa \\ Bruna Motta dos Santos \\ Zara Rego de Souza \\ Samira Cristina Silva Pereira \\ Jonas Roque Bendassoli ${ }^{1}$ \\ Marcelo Rodrigues Conceição ${ }^{2}$ \\ Antônio Carlos Ribeiro Andrade ${ }^{3}$
}

\section{RESUMO}

Esse trabalho tem como objetivo apresentar os resultados da pesquisa sobre o mercado de trabalho desenvolvida pelo projeto de extensão "A imaginação sociológica e sul de Minas". A imaginação sociológica diz respeito a percepção do modo como a vida particular dos sujeitos está intimamente vinculada a contextos sociais mais amplos. Segundo Mills, o indivíduo só pode compreender sua experiência, sua vida e avaliar seu próprio futuro localizando-se dentro da sociedade e da história mundial, passando, dessa forma, a ter noção de suas possibilidades e de seu papel enquanto sujeito. Tomando por base essa questão, esse trabalho pretende apontar maneiras de instigar a imaginação sociológica na sociedade sul-mineira, em especial nos alunos da Educação Básica, por meio da apresentação de dados secundários sobre o mercado de trabalho. Ao adquirem a compreensão de aspectos relativos ao mercado de trabalho, pretende-se causar nos alunos algum tipo de inquietação e despertar a capacidade de identificar as conexões entre cenários mais amplos e as esferas mais privadas da vida social.

Palavras-chave: Imaginação Sociológica. Dados Secundários. Mercado de Trabalho. Alfenas.

\footnotetext{
${ }^{1}$ Graduandos em Ciências Sociais na Universidade Federal de Alfenas. Integrantes do projeto de extensão "A Imaginação Sociológica e o Sul de Minas"

2 Professor no Instituto de Ciências Humanas e Letras da Unifal-MG. Coordenador do projeto de extensão "A Imaginação Sociológica e o Sul de Minas"

${ }^{3}$ Professor no Instituto de Ciências Humanas e Letras da Unifal-MG. Coordenador adjunto do projeto de extensão "A Imaginação Sociológica e o Sul de Minas"
} 


\section{INTRODUÇÃO}

Os projetos de extensão acadêmicos desenvolvem ações que possibilitam o compartilhamento de informações com o público externo à universidade e são uma das características fundamentais, junto ao ensino e a pesquisa, da maior parte das instituições públicas de ensino superior. $\bigcirc$ projeto em questão atende essa demanda da extensão universitária tendo como seu principal objetivo fomentar a discussão sobre a sociedade sul-mineira, tomando por base a análise de dados secundários extraídos de fontes oficiais, bem como democratizar o saber sociológico, tornando-o acessível à população do sul de Minas.

Nessa perspectiva de popularizar o saber das Ciências Sociais, o projeto se estrutura metodologicamente na noção de "imaginação sociológica" desenvolvida por Mills. Para Mills, a Sociologia possui um caráter central para vida de todos os sujeitos, sendo responsável por possibilitar a compreensão de como suas relações mais íntimas e particulares são afetadas por contexto sociais mais amplos. Nas palavras do autor, "o indivíduo só pode compreender sua própria experiência e avaliar seu próprio destino localizando-se dentro de seu período" (MILLS, 1982, p. 12) Dessa maneira, localizando-se histórico-socialmente, se pode perceber os horizontes das possibilidades humanas como demasiadamente maiores.

Nesse sentido, o projeto de extensão "A imaginação sociológica e o sul de Minas" se constitui nas dimensões do ensino, pesquisa e extensão e atua em parceria com as Escola Estaduais Padre José Grimminck e Dr. Emílio da Silveira e o jornal eletrônico "Alfenas Hoje". Entre as atividades desenvolvidas estão a coleta, análise, organização e apresentação dos dados secundários, bem como debates com os professores da rede pública a respeito da realidade dos alunos e o desenvolvimento de maneiras de instigar a imaginação sociológica através de planos de aulas. Tendo em mente o objetivo mais amplo do projeto em questão, pretende-se, nesse momento, trabalhar com os dados do mercado de trabalho, mais particularmente no cenário da microrregião e do municípo de Alfenas, dentro da ótica do conceito de Mills, esse recorte foi escolhido após ser apontado pelos professores da rede pública, parceiros do projeto, como um assunto de interesse dos alunos da Educação Básica. Desse modo, este trabalho é resultado desta primeira etapa da pesquisa realizada pelo projeto em questão.

Os dados aqui utilizados são dados secundários, ou seja, são informações já coletadas e acessíveis à toda população. Comumente ignorados, eles se constituem em um importante alicerce para a interpretação sociológica de 
diversas questões. Com o foco de pensar o tema do mercado de trabalho, extraímos os dados da Relação Anual de Informações Sociais (RAIS) do ano de 2015. A RAIS é um registro administrativo de periodicidade anual que tem por objetivo o suprimento das necessidades de controle da atividade trabalhista no país, o provimento de dados para a elaboração de estatísticas do trabalho, e a disponibilização de informações do mercado de trabalho às entidades governamentais.

Assim, os dados de cada setor foram examinados tendo em vista o Brasil, o estado de Minas Gerais, a microrregião de Alfenas e a cidade de Alfenas. Ao analisar os dados de cada região foi possível traçar um quadro comparativo e chegar a algumas conclusões. Por essa razão, o trabalho foi dividido nas seguintes partes: apresentação do conceito de imaginação sociológica, considerações acerca do mercado de trabalho do país, do estado de Minas Gerais, da microrregião de Alfenas e, por fim, de Alfenas. Nesse último item também se apresentará, além dos setores, quais as funções cujas ocupações detém o maior e menor número de vagas no ano de 2015. Esse levantamento de dados possibilitou um painel descritivo do mercado de trabalho formal em uma perspectiva macro e em uma perspectiva micro, proporcionando formas de instigar a imaginação sociológica tanto dos alunos da Educação Básica, quanto da população alfenense.

\section{IMAGINAÇÃO SOCIOLÓGICA}

Charles Wright Mills (1916-1962) foi o sociólogo responsável pela criação do conceito que permeia a proposta do presente trabalho. Nascido no Texas e doutor em Sociologia pela Universidade de Wisconsin, o autor centrou a maior parte de seus estudos na compreensão da desigualdade social. A primeira publicação de sua obra mais conhecida - "A imaginação sociológica" -, se deu em 1959 e buscava evidenciar para os sujeitos não-sociólogos a importância da Sociologia.

Nareferida obra, Mills afirma queavisão e a capacidade do homemseencontram limitadas pelo trabalho, família, vizinhos, dentre outros ambientes. Apesar de, em muitas dessas situações, os indivíduos permanecerem como espectadores, com a sensação de estarem cada vez mais encurralados, o sociólogo afirma que mudanças interpessoais também repercutem na estrutura da sociedade. Isso mostra-nos como a vida de qualquer indivíduo e a história da sociedade devem ser compreendidas em suas conexões mútuas, ou seja, no impacto recíproco que uma dimensão exerce sobre a outra. 
Nesse sentido, para Mills, é necessário que o homem perceba como sua vida privada está intimamente relacionada com a história mundial no sentido mais amplo. Os indivíduos, segundo o autor, raramente têm a consciência dessa ligação, de como seu cotidiano, bem como com suas sensações de bem-estar ou de angústia sofrem os efeitos de um cenário mais abrangente, pois "a história que atinge todo homem, hoje, é a história mundial" (MILLS, 1982, p.10). A compreensão dessa inter-relação estabelecida entre o eu e o mundo, entre o público e o privado, entre a biografia e a história é, para Mills, um dos objetivos da Sociologia. Sendo assim, é preciso auxiliar os indivíduos para que eles possam se utilizar das informações disponíveis para, então, pensar as questões nessa perspectiva.

O efeito de se despertar a imaginação sociológica no sujeito, de acordo com o autor, é a emergência da noção de que o indivíduo só pode compreender sua própria experiência, sua vida e avaliar seu próprio futuro localizando-se dentro da sociedade e da história mundial, passando, dessa forma, a ter noção de suas possibilidades e de seu papel enquanto sujeito. Assim, cabe a quem for realizar esse tipo de estudo, ter em vista três questões que são centrais para qualquer espirito que possua a imaginação sociológica:

1) Qual a estrutura dessa sociedade na história humana? Quais seus componentes essenciais, e como se correlacionam? Como difere de outras variedades de ordem social? Dentro dela, qual sentido de qualquer característica particular para a sua continuação e para a sua transformação? 2) Qual a posição dessa sociedade na história humana? Qual a mecânica que se faz modifica-se? Qual é o seu lugar no desenvolvimento da humanidade como um todo, e que sentido tem para esse desenvolvimento? Como qualquer característica particular que examinemos afeta o período histórico em que existe, e como é por ele afetada? E esse período - quais as suas características essenciais? Como difere de outros períodos? Quais seus processos característicos de fazer a história? 3) Que variedades de homens predominam nessa sociedade e nesse período? E que variedades irão predominar? E que formas são selecionadas, formadas, liberadas e reprimidas, tornadas sensíveis ou impermeáveis? Que tipos de "natureza humana" se revelam na conduta e caráter que observamos nessa sociedade, nesse período? E qual é o sentido que para a "natureza humana" tem cada uma das características da sociedade que examinamos? (MILLS, 1982, p.12). 
Nesse ínterim, são três as características que compõem a imaginação sociológica: a História, a biografia e a estrutura social. Para entendermos a experiência individual e também podermos nos avaliarmos dentro do contexto do qual fazemos parte, devemos buscar compreender a sociedade, os processos de mudança desta e como vem sendo construída sua história, no intento de compreender, assim, a natureza humana na sociedade, o que mantem sua coesão e o que impulsiona tais transformações. (MILLS, 1982)

Alguns autores mais contemporâneos também têm se preocupado com a questão, entre eles o sociólogo inglês Anthony Giddens. Através de uma análise dos aspectos que caracterizam o período, denominado como modernidade tardia, o autor mostra-nos como as transformações sociais mais amplas repercutem, também, nas dimensões privadas da vida dos sujeitos. Segundo o autor, o mundo contemporâneo é um contexto marcado pelo dinamismo, no qual as consequências atingem elementos tradicionais já estabelecidos, trazendo uma conexão social em termos globais, cujos elementos estão intimamente vinculados com as disposições pessoais. (GIDDENS, 1991)

Giddens afirma que, se por um lado, o mundo contemporâneo trouxe formas de vida mais seguras e satisfatórias, trouxe consigo, também, uma faceta negativa e sombria, como as ameaças de desastres em escala global, uma guerra nuclear ou catástrofe ecológica. Com a separação do espaço e tempo, aliada aos mecanismos de desencaixe, as atividades sociais ocorrem sem que o cenário local seja imprescindível, removendo as relações sociais do contexto imediato. Nesse cenário, os sujeitos possuem a consciência dos riscos de suas ações e, com isso, possuem um sentimento de ansiedade que é constante, apesar de desenvolverem mecanismos para possuírem capacidade de seguir em frente em suas atividades rotineiras. (GIDDENS, 2002)

Nesse sentido, é central em toda a teorização de Giddens a noção de reflexividade. Segundo o autor, os sujeitos examinam constantemente suas ações e, tal conduta se configura como o fundamento da ideia de reflexividade. Em cenários pré-modernos, esse monitoramento era efetuado com base na tradição, associando tempo e espaço na estruturação dos comportamentos. Com a emergência da modernidade tardia, surge uma nova forma de monitoramento das ações, consistindo no exame e reestruturação constante das práticas tendo por fundamento o conhecimento produzido acerca destas. Dito de outro modo, a reflexividade, para Giddens, diz respeito à incorporação de conhecimento e informações, produzidos e renovados, que impactam a dimensão do social, 
reestruturando e alterando a natureza das atividades cotidianas. (GIDDENS, 1991)

Ao tratar do conhecimento sociológico e sua conexão com os aspectos definidores da modernidade tardia, Giddens pontua como as noções criadas no âmbito das Ciências Sociais retornamaocenárioanalisado. Assim, o conhecimento sociológico, possuiria, para o autor, uma centralidade, pois, detendo um saber generalizado acerca do social e introduzindo-se nos mais diferente âmbitos da vida dos sujeitos, reconstrói tanto a dimensão social quanto a si mesmo. Esse impacto exercido pelo conhecimento sociológico, seria, segundo Giddens, uma característica intimamente envolvida no que é a modernidade. (GIDDENS, 1991)

O discurso da sociologia, seus conceitos, teorias e descobertas das outras ciências sociais continuamente "circulam dentro e fora" daquilo de que tratam. Assim fazendo, eles reestruturam reflexivamente seu objeto, ele próprio tendo aprendido a pensar sociologicamente. A modernidade é ela mesma profunda e intrinsecamente sociológica. (GIDDENS, 1991, p. 53)

\section{METODOLOGIA}

Os dados utilizados no presente trabalho foram os dados secundários, disponíveis na RAIS, plataforma que contém o maior número de dados que contempla os objetivos do projeto. Assim, optamos por trabalhar somente com os dados referentes ao ano de 2015, por esse ser o período mais atual com disponibilidade de informações sobre o mercado de trabalho. Os levantamentos são referentes ao mercado de trabalho formal nos âmbitos: nacional, estadual, regional e local, e seguem um dos critérios específicos do Instituto Brasileiro de Geografia e Estatística (IBGE) - atualmente o principal provedor e divulgador de dados nacionais - quanto a divisão de setores e postos de trabalho. Realizamos, também, o levantamento de dados pertinentes a Alfenas, que referem-se à Classificação Brasileira de Ocupação (CBO). A CBO permite a visualização de um extenso número de ocupações e, por isso, foi selecionada.

Foram escolhidos, dado o recorte do presente trabalho, determinados setores e suas relações com o número de empregados presentes na plataforma da RAIS. Para coletar esses dados foi preciso acessar o site do Ministério do Trabalho e Emprego (MTE) e escolher o número de vínculos ativos da RAIS nos anos corrente à 2002. Foram, então, delimitadas as localidades que seriam trabalhadas e, como 
assunto, buscamos a divisão setorial feita pelo IBGE. Em um segundo momento, foram extraídos os dados do subgrupo de ocupações somente de Alfenas conforme os critérios da CBO.

A análise do número de empregados por setor corresponde ao total de vínculos efetivados no período de um ano. Os setores de atividade econômica se dividem de acordo com os seguintes critérios: os produtos produzidos, os recursos e as formas utilizadas em sua produção. Oito setores de atividade econômica serão analisados e foram escolhidos por apresentarem um panorama geral da quantidade de empregados por área vinculados no ano 2015, esses setores são: o extrativismo mineral; a agropecuária, extração vegetal, caça e pesca; a indústria de transformação; os serviços industriais de utilidade pública; a construção civil; os comércios; os serviços e a administração pública. Desse modo, a partir do levantamento de dados, foi desenvolvida uma reflexão buscando promover a discussão sobre a imaginação sociológica com os estudantes e, por meio de artigos jornalísticos, com toda a população alfenense.

\section{MERCADO DE TRABALHO NO BRASIL}

Ao analisar o percentual de cada um dos setores do Brasil, é possível destacar que o setor de Serviços aparece com 36\%, uma porcentagem muito maior que os outros sete setores. Em segundo lugar aparece o setor de Comércio com 20\% e, bem próximo dessa porcentagem, o setor de Administração Pública com a taxa de empregos formais correspondendo a $19 \%$.

Vale lembrar que as estruturas que mais ofertam emprego, no caso o setor de Serviços e o setor de Comércio, possuem menores taxas de acumulo de capital e, consequentemente, menores salários.

No gráfico 1 está exposta essas porcentagens, ou seja, o número de empregos formais por cada setor de atividade econômica no Brasil em 2015. Nele também é possível notar que o quarto setor que mais emprega é a Indústria de Transformação com a taxa de 16\%. O setor de Agropecuária, Extração Vegetal, Caça e Pesca; e o setor Serviços Industriais de Utilidade Pública ocupam as próximas posições e possuem uma taxa de 3\% e 1\% respectivamente. 
Gráfico 1 - Número de Empregos Formais Segundo Setor de Atividade Econômica: Brasil - 2015

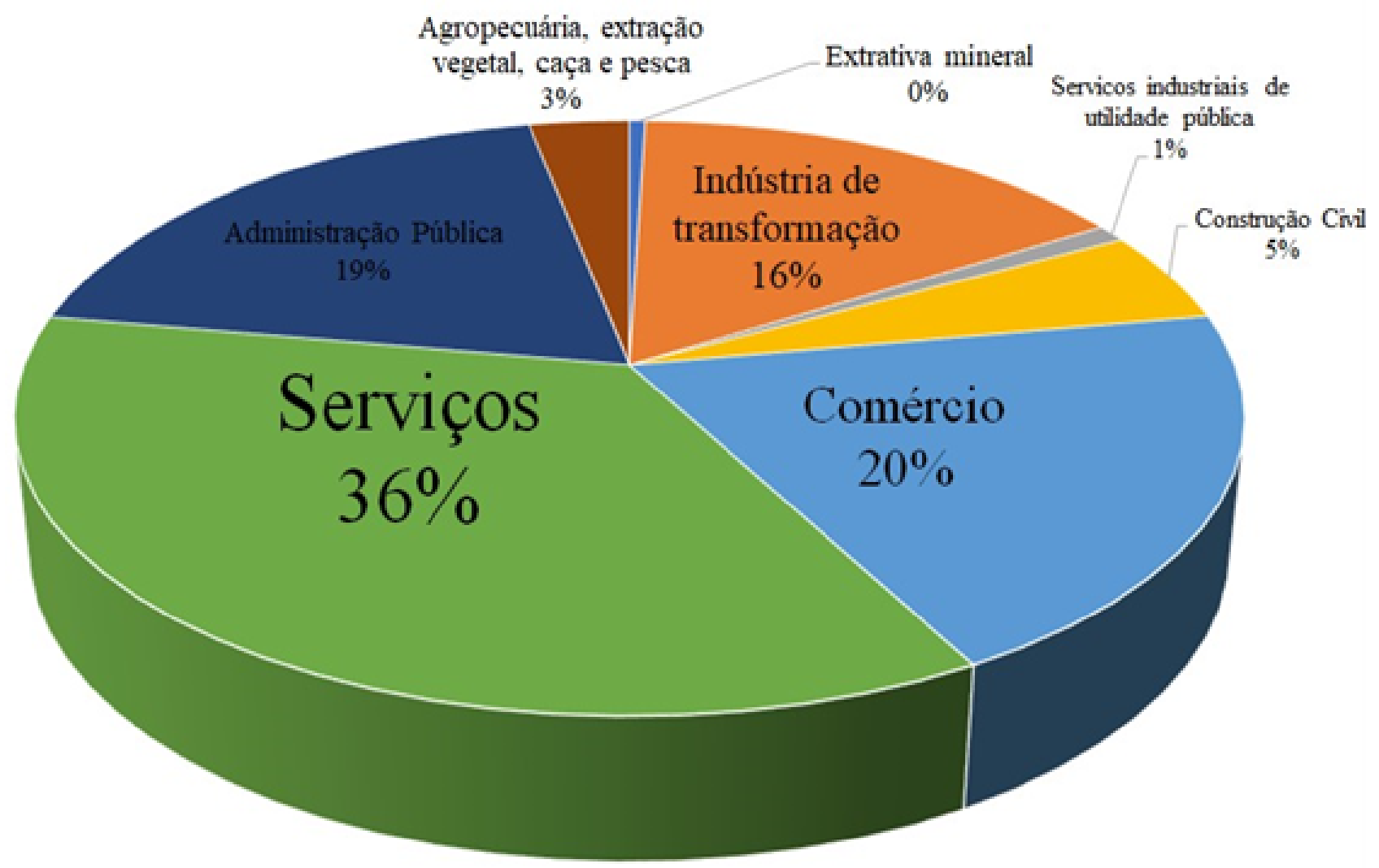

Fonte: RAIS 2015. Elaboração própria.

\section{MERCADO DE TRABALHO EM MINAS GERAIS}

O mercado de trabalho de Minas Gerais também se destaca por mais da metade das vagas de emprego serem oferecidas pelo o setor de Serviços e o setor de Comércio. O setor de serviços possui a taxa de 33\% e o de Comércio 21\%.

No gráfico abaixo também é possível destacar que o setor Administração Pública e o setor Indústria de Transformação possuem valores quase idênticos, o primeiro 17\% e o segundo 16\%. Já o setor da Construção Civil vai empregar uma taxa de 6\% e a Agropecuária, Extração Vegetal, Caça e Pesca 5\%, também 
valores muito semelhantes. Por fim, ocupando a taxa de 1\%, estão os setores da Extrativa mineral e de Serviços industriais de utilidade pública.

Gráfico 2 - Número de Empregos Formais Segundo Setor de Atividade Econômica: Minas Gerais - 2015

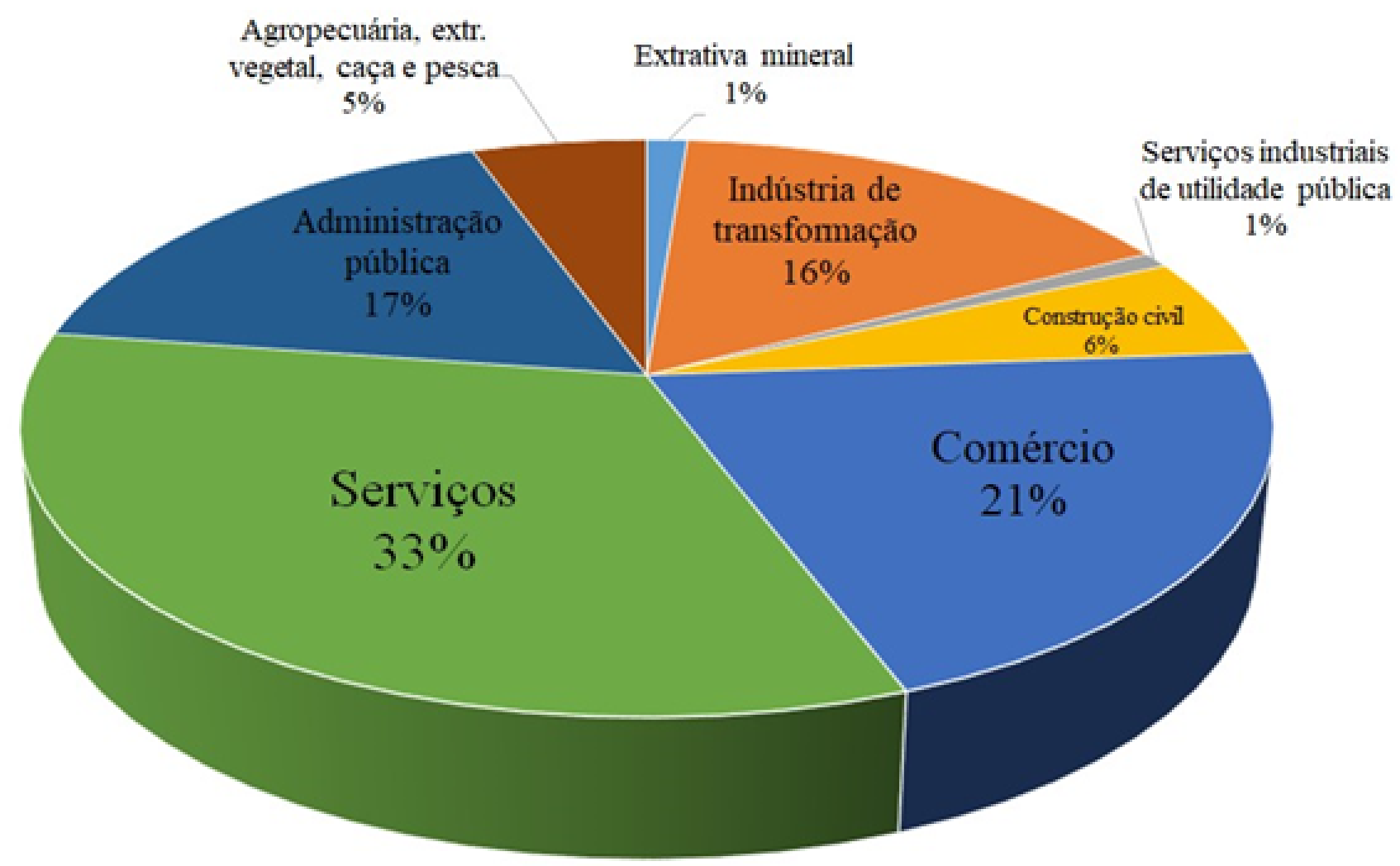

Fonte: RAIS 2015. Elaboração própria.

Alguns setores econômicos, pensando o País e o estado, se mantém com valores semelhantes. Por exemplo, o setor de Serviços em Minas Gerais sofre um declínio de apenas 8,33\% se comparado com o País; diferentemente do setor de Extrativa Mineral que tem um aumento de 100\% no estado comparando com o Brasil.

Aprofundando as comparações entre o País e Minas Gerais, pode-se apontar que apesar dos setores: de Comércio; da Construção Civil; da Extrativa Mineral e da Agropecuária, Extração Vegetal, Caça e Pesca, terem um aumento no estado de Minas Gerais em relação ao Brasil, e setor de Serviços e o setor de 
Administração Pública terem um declínio, todos os setores econômicos listados ocupam a mesma posição ao se comparar os âmbitos nacional e estadual.

\section{MERCADO DE TRABALHO NA MICRORREGIÃO DE ALFENAS}

A análise da microrregião da cidade de Alfenas foi pensada por ela oferecer aos alunos da Educação Básica uma noção melhor de deslocamento de acordo com seus anseios futuros. Por exemplo, se houver estudantes que visam trabalhar em determinado setor econômico, mas veem que esse emprego está em falta no seu município, através dos dados das cidades próximas a Alfenas, ele pode ver se mudar é ou não uma opção para ele após o término do Ensino Médio.

O gráfico 3 apresenta, portanto, o número de empregos formais por setor de toda a microrregião de Alfenas. Essa microrregião é composta pelas seguintes cidades: Alterosa, Areado, Carmo do Rio Claro, Carvalhópolis, Conceição da Aparecida, Divisa Nova, Fama, Machado, Paraguaçu, Poço Fundo e Serrania. Todas essas cidades são de suma importância para a atuação projeto, já que o mesmo visa trabalhar a imaginação sociológica em todo o sul de Minas.

O percentual de empregos formais segundo os setores de atividade econômica são, em ordem crescente, os seguintes: Serviços Industriais de Utilidade Pública com 1\%; Construção Civil, 3\%; Administração Pública; e Agropecuária, Extração Vegetal, Caça e Pesca com 14\%; a Indústria De Transformação ocupa o terceiro lugar tendo a taxa de 17\%; o Comércio possui 23\%; e, por fim, os Serviços com $28 \%$.

Ao se analisar a microrregião de Alfenas, diversas outras mudanças podem ser apontadas. Uma delas é que o maior aumento na microrregião de Alfenas em relação ao estado e ao País se dá no setor de Agropecuária, Extração Vegetal, Caça e Pesca; enquanto existe uma diferença de 180\% comparado com Minas Gerais, ao se observar a tabela 1, há um aumento de $366 \%$ se comparado ao Brasil. Se determinado setor gera mais empregos, consequentemente o percentual dos outros setores será menor, por isso, o setor de Serviços tem uma queda de 15,15\% em relação ao estado e de 22,22\% em relação ao Brasil. Entretanto, vemos que o setor Comércio se mantém relativamente semelhante em todas três regiões. 
Gráfico 3 - Número de Empregos Formais Segundo Setor de Atividade Econômica: Microrregião de Alfenas - 2015

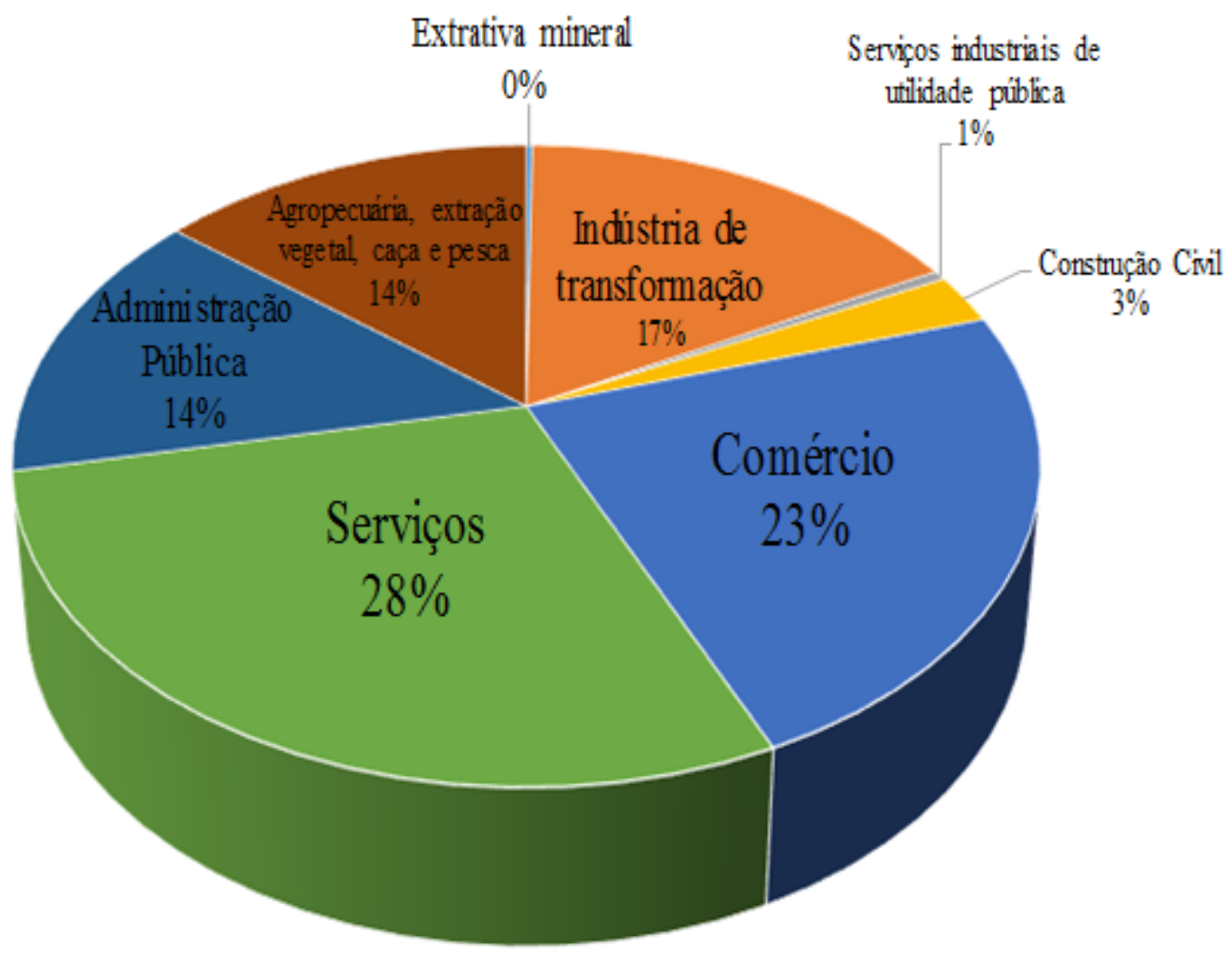

Fonte: RAIS 2015.Elaboração própria.

\section{MERCADO DE TRABALHO EM ALFENAS}

Em Alfenas o setor de Serviços aparece com uma taxa muito alta, 41\%. Em contrapartida, os setores Extrativa mineral e Serviços industriais de utilidade pública não atingem um por cento, como pode-se notar no quarto gráfico.

As posições centrais referentes a cada setor econômico são ocupadas decrescentemente por: Comércio com 26\%; Agropecuária, extração vegetal, caça e pesca com 10\%; Indústria de transformação com 10\% e Construção Civil com 3\%. 
Gráfico 4 - Número de Empregos Formais Segundo Setor de Atividade Econômica: Alfenas - 2015

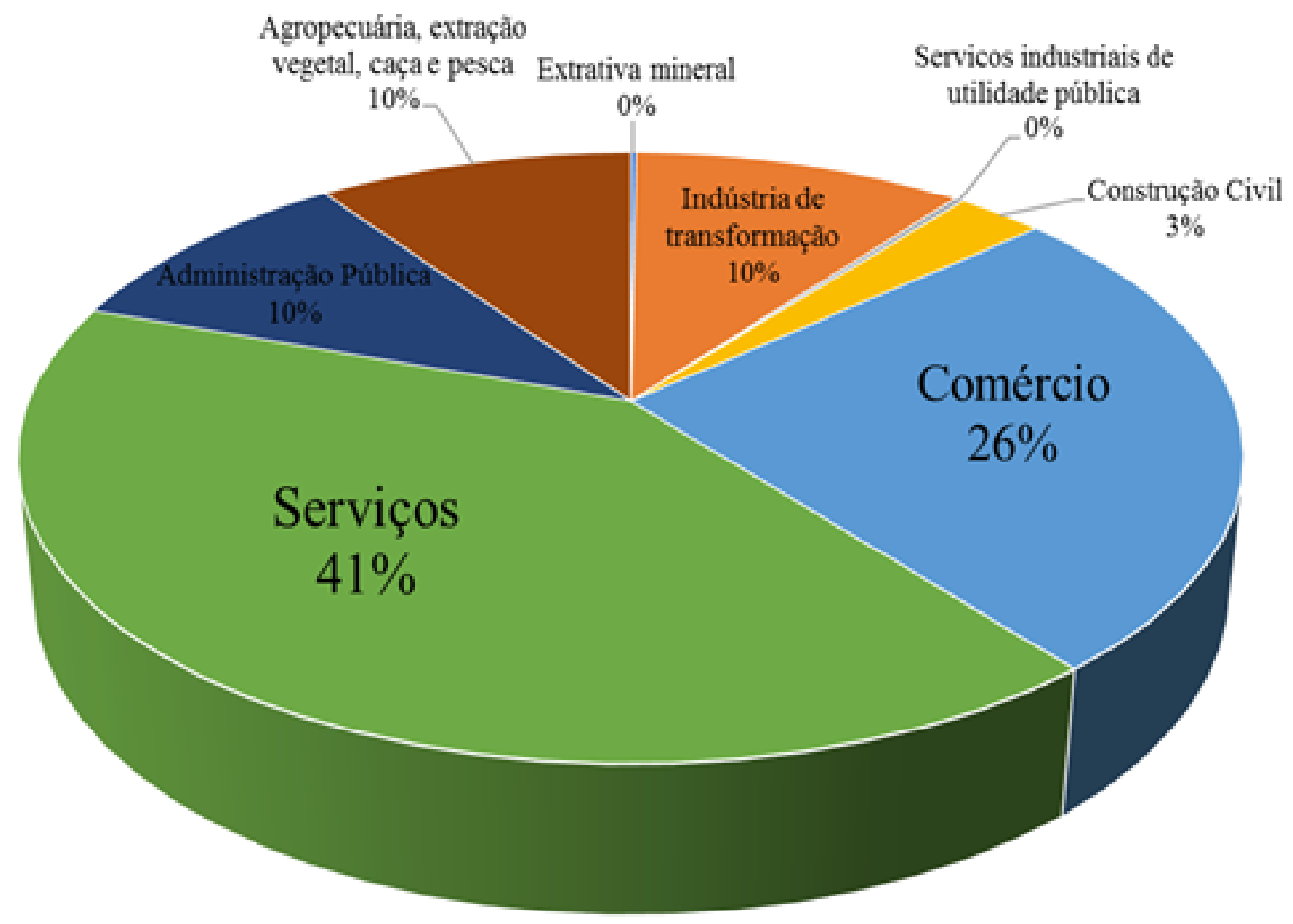

Fonte: RAIS 2015. Elaboração própria.

Dessa forma, no gráfico 4, os setores que apresentam o maior percentual são: Serviços e Comércios. Em contraposição, os que apresentam percentuais mínimos são: Extrativa Mineral, Serviços Industriais de Utilidade Pública e a Construção Civil.

Alfenas também é a localidade que apresenta maior número de variantes percentuais significativas. Sendo assim, o número de empregos formais segundo o setor Serviços aumenta consideravelmente, possuindo o percentual de 41\%, aumento de 13,88\% em comparação com o Brasil, aumento de 24,24\% em relação a Minas Gerais e de 46,42\% quanto a microrregião de Alfenas.

O Comércio também sofre um aumento, mas outra notável discrepância nas taxas são os percentuais dos setores de Administração Pública e do setor 
Indústria de Transformação. O primeiro tem o percentual de 10\% em Alfenas, é uma taxa menor em 28,57\% em relação à sua microrregião, aumento de 23,80\% se comparar com o estado e um aumento de $30 \%$ se equiparado ao País. Já o segundo setor listado, assim como a Administração Pública, possui a taxa de 10\%, ou seja, 70\% a menos que a região, queda de 41,17\% que o estado de Minas Gerais e queda de 47,36\% comparado ao Brasil.

A Tabela 1 permite visualizar de forma mais sintética os resultados da pesquisa em questões e é possível pensar as oscilações dentro do mercado de trabalho que ocorrem quando se reflete acerca das possibilidades profissionais de todo o país e, em especial, do sul de Minas e de Alfenas.

\begin{tabular}{l|c|c|c|c}
\hline \multicolumn{1}{c}{$\begin{array}{c}\text { Setores de Atividade } \\
\text { Econômica }\end{array}$} & Brasil (\%) & $\begin{array}{c}\text { Minas } \\
\text { Gerais (\%) }\end{array}$ & $\begin{array}{c}\text { Microrregião de } \\
\text { Alfenas (\%) }\end{array}$ & Alfenas (\%) \\
\hline Extrativa Mineral & 0,50 & 1,25 & 0,23 & 0,17 \\
Indústria de Transformação & 15,74 & 15,93 & 16,93 & 10,43 \\
$\begin{array}{l}\text { Serviços Industriais de } \\
\text { Utilidade Pública }\end{array}$ & 0,93 & 0,88 & 0,49 & 0,27 \\
Construção Civil & 5,04 & 5,63 & 2,56 & 2,75 \\
Comércio & 19,83 & 20,64 & 23,13 & 25,55 \\
Serviços & 35,69 & 33,11 & 28,42 & 41,10 \\
Administração Pública & 19,14 & 17,18 & 14,11 & 9,78 \\
Agropecuária, extração & 3,12 & 5,38 & 14,12 & 9,97 \\
vegetal, caça e pesca & & & &
\end{tabular}

Fonte: RAIS 2015. Elaboração própria.

Visando o interesse dos alunos da Educação Básica de rede pública de ensino, extraímos dados da CBO referentes à Alfenas que confirmam os dados acima, foram levantadas, ao todo, 151 ocupações que preenchem 19.956 vagas, sendo essas organizadas em termos de ocupações com maior número de vagas e as com o menor número de vagas.

As profissões que mais preenchem vagas na cidade são: vendedores e demonstradores com 2.275; escriturários em geral, agentes, assistentes e auxiliares administrativos com 1.808; trabalhadores no serviço de administração, conservação e manutenção de edifícios e logradouros com 1.294 e condutores de veículo e operadores de equipamentos de elevação e de movimentação que 
possuem 953 das vagas preenchidas. No que tange os setores com o menor número de empregos formais, as profissões que também ocupam menos vagas, na verdade, apenas uma vaga são: matemáticos, estatísticos e afins; membros de cultos religiosos e afins; técnicos em operação de aparelhos de sonorização, cenografia e projeção; trabalhadores em acabamento de madeira e de mobiliário, operadores de instalações e equipamentos de produção de metais e ligas; trabalhadores artesanais de siderurgia e de materiais de construção; e, por fim, trabalhadores da preparação de pasta de papel.

\section{CONSIDERAÇÕES FINAIS}

O conceito de imaginação sociológica proposto por Mills, pode ser pensado, primeiramente, na medida que traçamos um painel comparativo que vai do macro (Brasil) ao micro (Alfenas), e também ao fazermos os estudantes do Ensino Médio se localizarem histórico-socialmente e pensarem algumas questões como, por exemplo, as possíveis razões de membros da sua família não encontrarem empregos em Alfenas e se a carreira que eles desejam seguir é possível se permanecerem no sul de Minas.

A apresentação dos dados e conceitos tanto para os estudantes, como para a população sul-mineira, só foi possível pela Sociologia e, ao fazer esse tipo de análise atribuímos a importância que a matéria merece e mostramos as diversas ferramentas que ela trabalha e os resultados que ela pode produzir. Popularizar esses dados e exercitar a imaginação sociológica também permite proporcionar à população aparatos de construção de um saber próprio, uma vez que essas informações estão disponíveis a todos. Por isso, o objetivo do trabalho, está para além de levantar e analisar dados secundários, mas também fornecer aos indivíduos maneiras de localizar e interpretar esses dados, bem como compreender como essas referências podem afetar até mesmo a dimensão mais privada da vida de todos os sujeitos. 


\section{REFERÊNCIAS BIBLIOGRÁFICAS}

GIDDENS, Anthony. As consequências da modernidade. São Paulo: Ed. UNESP, 1991.

GIDDENS, Anthony. Modernidade e Identidade. Rio de Janeiro: Jorge Zahar, 2002

IBGE. 2017. Instituto Brasileiro de Geografia e Estatística. Informações disponíveis em < http://www.ibge.gov.br/home/>. Acesso em 30 de junho de 2017.

MILLS, Charles Wright. A Imaginação Sociológica. 6 ed. Tradução: Waltensir Dutra. Rio de Janeiro: Zahar Editores, 1982.

RAIS. 2015. Relação Anual de Informações Sociais. Dados disponíveis em

< http://bi.mte.gov.br/bgcaged/rais.php>. Acesso em 26 de maio de 2017. 